\title{
The Efficacy Of Remedial Education Program On Houston's At Rick Youth
}

Brigett T. Bentley, (E-mail:BBentley@Central.uh.edu), University of Houston-Victoria

Gbolahan Solomon Osho, (E-mail: OshoS@uhd.edu), University of Houston - Downtown

\begin{abstract}
There is universal agreement that a good education for all our citizens is the harbinger of future personal success, a high standard of living, and a flourishing economy and improved global competitiveness. Actions that contradict that postulate must therefore be challenged, exposed and corrected. Remedial academic programs have effectively supplemented our core educational systems and elevated many minority sectors of our nation to productive contributions. A realignment of priorities influenced by political interests and budget constraints is threatening the continuity of these programs despite significant returns on investment. This paper explores the demographics of Houston's minority education, the effectiveness of remedial initiatives on at risk youth graduation outcomes and collaborative solutions to replicate and preserve the progress achieved.
\end{abstract}

\section{Introduction}

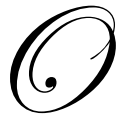

ur nation and more directly, our local communities are faced with one of the most insidious threats to our national vitality, the escalating educational deficits of our economically and socially disadvantaged children. More narrowly defined, this paper examines the plight of this sector in Houston, Texas, its demographics, its challenges, and the assessment of remedial solutions on possible educational outcomes. Its empirical perspectives are informed by the work of EDUCATION $4 \mathrm{U}(\mathrm{E} 4 \mathrm{U})$ - a business enterprise established in 2002 to provide remedial tutorial services to Houston's at risk youth community. It operates under the auspices of THE WORKSOURCE - Houston Works Youth Opportunity (YO) - a federally funded program that provides youth education training and workforce development services to more than 425,000 individual residents throughout the region.

With increasing complexity, our globally interdependent economy faces fierce competition that requires a well-educated, highly skilled and productive workforce. Yet, studies continue to expose serious skill deficiencies when American students are ranked with those of other nations. Further erosion of math and science graduates poses enormous problems for American research and industry. As a nation, we simply cannot afford to leave any segment of our population behind. However, there is mounting evidence to the contrary, as inequities in education between urban and suburban schools condemn inner city students to inferior outcomes.

\section{DEMOGRAPHICS}

The student population served by E4U is defined as "at risk". This designation is identified with one or a combination of the following non-prioritized characteristics: an ethnic minority, single parent, low income, limited parental education, family on government assistance, one or more family member is a high school dropout, poor current academic performance, overage for current grade level, disciplinary and/or truancy-related problems, adult responsibilities (working and/or pregnancy), criminal activity, low self-esteem and a detached outlook to control their own destinies (Gleason, p.2-3). In essence, these are subsets of poverty, its culture and its repercussions.

In 2003, 41 percent of low-income families in the U.S. lived in the southern states (Geography of low income families and children-Figure 1). 


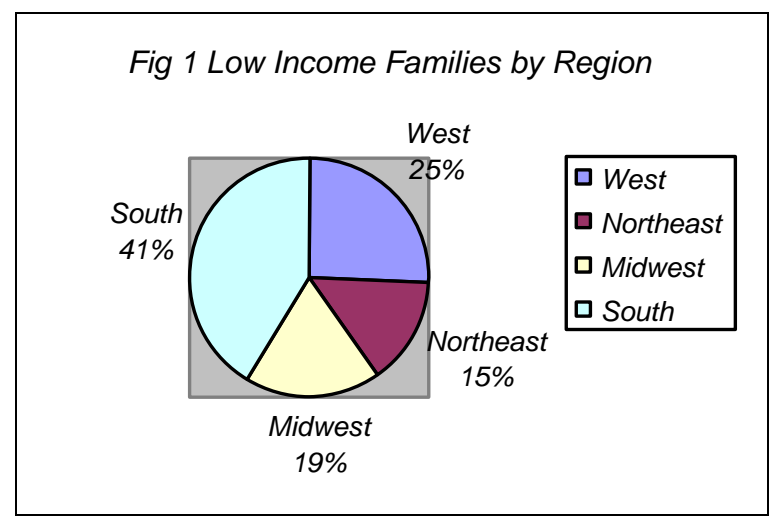

For Texas, 24.2 percent of these families are near poverty and 17 percent are at or below the poverty line. $(\$ 18,400 / \mathrm{yr}$-family of 4$)$, exceeding the national average of 11.8 percent. Within Harris County, Hispanics represent 33 percent of the population and blacks 18 percent. About 66 percent of Latino children and 51 percent of black children are impoverished, the majority of which reside in the inner cities of Texas.

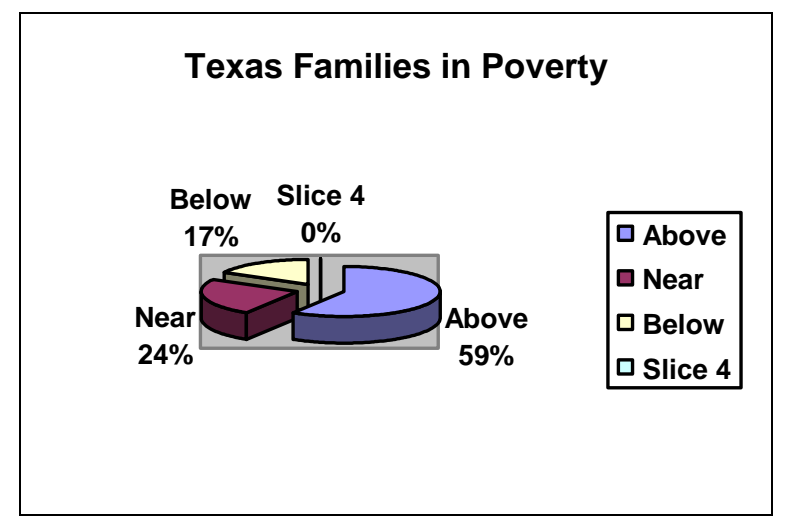

The 2004 Harris County Profile cited 19.95 percent of its population less than 18 years of age in poverty. Even more surprising, the Houston Independent School District (HISD) reports that 27.92 percent of its enrolled student population conforms to this classification (Texas County Profiles).

Given these statistics, it is not surprising that by far, the biggest challenge to urban education is concentrated poverty. It is the most important risk factor that impedes educational development. In high-poverty schools, students are full three grades behind the students in low-poverty schools, according to a recent U.S. Department of Education report classification (School finances, poverty charts).

\section{THE CHALLENGES}

Minority populations in urban centers are most at risk. In Houston, this population is concentrated in the Wards $-1^{\text {st }}, 2^{\text {nd }}, 3^{\text {rd }}, 4^{\text {th }}$ and $5^{\text {th }}$. Some of these communities are in a natural transition while others are experiencing severe upheaval as new high value development encroaches on historical minority neighborhoods. These are the communities that fall under the purview of Houston Works Youth Opportunity (YO). Services are provided through four youth centers and four school-based sites. The network offers youth programs that address a wide range of supportive and remedial needs including education, training and employment for in-school students and out-ofschool youth. Central to the in-school program is the objective to graduate students with the appropriate skill 
competencies for a successful collegiate experience. Four area high schools participate in the program: Phyllis Wheatley, Stephen F. Austin, Jack Yates, and Jeff Davis. Activities in the schools are designed to encourage students to stay in school and provide them with the tools needed to succeed.

Despite these efforts, poverty imposes enormous burdens on inner city public schools mandated to accept all students regardless of their economic and social status. There are inherent dangers of urban life. Many neighborhoods may be depressing, discouraging, hostile environments for young people. Research indicates that the ravages of alcoholism, systemic unemployment, illiteracy, welfare dependency, criminal activity, depression, and domestic family violence are major problems throughout these communities. Recreational, educational and employment opportunities for rural youths and adults are often limited. Many inner-city youth reside in neighborhoods so crime-ridden that it is dangerous to play outside. Adult leadership in these communities may be ineffective and disorganized, and in the absence of parental authority, young people may seek protection, camaraderie, and "career opportunities" in gangs and the drug trade.

Alternatives to street life may appear slim. Youth in these minority communities have fewer programs and a narrower range of activities to participate in than do young people in white suburban communities. A shrinking tax base precipitated by economic blight and the flight of the middle class from urban to suburban communities has devastated the revenues that would ordinarily fund these activities. As a consequence, at risk youth may have fewer opportunities to receive adult guidance and supervision, explore and expand their interests, discover career alternatives, augment skills, exhibit competency, and experience a sense of connection and belonging.

The declining economies of Houston's urban areas may intensify community problems. As earnings of young, non-college-educated males fell sharply, and many young families in these communities slipped below the poverty line. Affordable housing has become increasingly difficult to locate, thus many young families have been forced into inadequate dwellings. Inadequate shelter -- or not having a home at all -- may increase accidents, disease, and delinquency among children and youth (State of Education Report).

\section{REPERCUSSIONS}

Inner city public schools - faced with such overwhelming obstacles to learning are struggling to find appropriate solutions. Surrounded by social and economic decay, many schools are not capable of marshalling the type of financial and professional resources to fully engage in stripping away the vestiges of poverty that is robbing our youth of their future. In a recent report of high school graduation rates, Texas ranks $40^{\text {th }}$ among the 51 states, graduating 67 percent of its students but only 59 percent of blacks and 56 percent of Latinos. These results compare with the national average of 71 percent followed by 56 percent for Blacks and 54 percent for Latino students. By district, HISD posted a ranking of 43 out of 50 districts (Greene, p. 11-15). Texas students averaged 874 on the Scholastic Aptitude Test (SAT) as compared to the national average of 900 suggesting a less-prepared student population. In its State of Education report, the State of Texas identified 26 percent of $9^{\text {th }}$ grade students and 24 percent of $12^{\text {th }}$ grade students as at risk for future academic problems over time.

Houston's dropout rate has been a subject of some dispute however, data provided by the State of Texas reveals that 53,965 students dropped out during the 1991-2 period or 3.9 percent. Latinos had the highest dropout rate of 5.6 percent followed by blacks with 4.8 percent and white students had a below average rate of 2.7 percent. Minority students' account for 69 percent of total dropouts. The Texas Education Agency also estimated a longitudinal rate measuring total dropouts between the $7^{\text {th }}$ and $12^{\text {th }}$ grades for the $1991-2$ period to be 21 percent.

Many studies have concluded that risk factors do not predict exactly who will be a dropout. Some dropouts have no risk factors and some students with many risk factors stay in school. Researchers found that poor attendance best predicts whether students will drop out but it is not highly predictive of dropping out (Gleason, p. 17-18). 


\section{REMEDIAL INTERVENTIONS}

Houston Work Source Youth Opportunity program formed collaboration with E4U to provide critical academic remediation services for its inner city at risk youth, specifically the $3^{\text {rd }}$ and $5^{\text {th }}$ wards. E4U's basic methodologies conform to recent findings that successful intervention strategies must include intensive customized remedial programs based on individual skill assessments and aptitudes. Options for academic intervention could be comprehensive covering a range of subject disciplines or targeted to specific deficiencies. As a matter of policy, the initial implementation of the program in 2003 allowed for much wider latitude to include sustained academic development components as well as limited subject-specific skill upgrades as needed. Students seeking significant performance improvements could at least be confident that an appropriate program of sufficient duration would be designed to achieve the objective. However, recent policy shifts and management mandates have resulted in a program structured more to intercede in a crisis management format than designed to achieve genuine academic proficiency for both in school and out-of school youth.

Students in academic jeopardy can self-refer or are recommended by YO's- youth development specialists to participate in E4U's direct tutorial program. For most students, their primary objective is test preparation and obtaining passable scores. Often, their expectations are unrealistic given the limited time within which to rehabilitate severe deficiencies. Despite these shortcomings, E4U successfully assisted students to achieve scores that enabled them to advance. Unfortunately, this success betrays the reality that for most of these students, skills acquired in this way are transient and incapable of providing the necessary foundation to develop more advanced competencies demanded by our complex society.

Unlike the public school environment, tutorial participation is highly interactive and individual, permitting a deeper understanding of the students' knowledge deficits and other social, emotional or economic disincentives to learning. Students do benefit in varying degrees depending on external influences that fall outside the control of instructors. To fully absorb the subject matter, students must be disciplined to practice the skill sets in other settings with sufficient repetition. Assignments must be studied and completed as required to instill confidence. Concepts must be applied until they are mastered as a result of committed determination on the part of the student. For students at risk, the ravages of poverty often disrupts the best of intentions as students are confronted with dysfunctional homes and crime-infested neighborhoods that they are helpless to change. Miraculously, some persevere and achieve excellence, but most succumb, defeated by circumstance and unable to achieve their true potential.

There is complicity with the very institutions that are charged with supporting minority communities. Political prerogatives of the ruling party effect government-sponsored programs. Ideologically opposed programs result in budget constraints that often thwart, reverse or restrict progress. Despite the rhetoric, Republican administrations tend to reduce funding allocations directed at the social safety net. Such reductions took effect in 2003 and produced contractions in services to Houston's minority communities. Students requiring the most intensive remedies are sacrificed regardless of measurable improvements as limited resources reduce the effectiveness of proven services. Management strategies are employed that discourages student participation in academic services except for strictly short-term surgical rehabilitation efforts certain to obtain only superficial results. Misleading accountability measures are applied to service providers to justify service restrictions or elimination.

To be sure, these actions are shortsighted. At risk youth facing these obstacles disengage from the system and become significant burdens on both state and federal budgets. Any attempts at future remedial interventions are exponentially more difficult and costly. The State of Education report points out that one-dollar invested in youth intervention programs can save $\$ 5$ to $\$ 7$ in prison costs and a $\$ 30$ million dollar investment would yield a return of $\$ 210$ million over the lifetime of the youth. Similarly, the $\$ 4,600$ per year Texas spends on public education per child pales in comparison to the $\$ 16,136$ per year to support an inmate in state prison. Armed with these sobering facts, it is difficult to fathom that with such economic and investment incentives, the most vulnerable among our population continues to struggle for access to even the most basic of services, most of all educational services. It's 
the only alternative that offers the promise of transforming our under performing minority assets into productive assets and responsible citizens.

\section{RECOMMENDATIONS}

Keeping at risk students in school is by far the least expensive solution even if it requires supplemental and remedial services. To expect efficiencies and effective reforms from school restructuring in these depressed communities is wishful thinking (Dynarski, p. 4-5). In the four Houston schools that serve as the hub for the YO programs, minimal improvements were achieved from such initiatives as school-based governance, school councils, outcome-based education, counseling and attendance monitoring. In fact, schools that considered restructuring found it more convenient and cost efficient to add remedial academic intervention services. Changes to in-school teaching methodologies proved fragile and vulnerable to shifting district leadership and political interests.

Remedial programs proved most effective when implemented as early as possible before students have left school and before they are so far behind academically and alienated from school emotionally that dropping out seems the only logical alternative. For at risk students in middle schools, a more intensive approach to fundamental mathematics, algebraic and English core prerequisites resulted in improved performance and enabled the acceleration of academic progress to age and grade-appropriate levels (Dynarski, p. 6).

At risk high school students were generally more oriented towards passing the assessment tests, preferring to focus on test-taking strategies. It should be noted that high school students that dropped out early in the $12^{\text {th }}$ grade were unlikely to return the complete the requirements of the high school diploma. The General Education Diploma (GED), with its less rigorous curriculum requirements, was the outright preference of this student sector.

For at risk youth of Houston's inner city, reliance on remedial academic intervention is an integral part of successful graduation outcomes. However, to fairly judge the efficacy of each intervention is contingent upon the original objective desired - be it core skills enhancement or tertiary advancement. In general, the skillful employment of remedial intervention strategies by qualified service providers strengthens the arsenal of educators to break the bondage of poverty and empower at risk minority youth to pursue excellence. Common sense, backed by research, suggests that at-risk youth and their families have multiple needs that are not successfully addressed by single-response, stand-alone initiatives. A child may be at risk because of one factor or a combination of causes, but it takes the concerted efforts of families, schools and communities to put at-risk youth back on the path toward success.

\section{References}

1. Dynarski, M., Gleason, P. (1999). "How Can We Help? Lessons From Federal Dropout Prevention Programs," Policy Brief from Mathematical Policy Research, Inc. 1-10.

2. Gleason, P., Dynarski, M. (1998). "Do we know whom to serve? Issues using risk factors to Identify dropouts," Submitted by Mathematical Policy Research, Inc.P.1-21, A1.

3. Texas demographics, National Center for Children in Poverty, Columbia University Mailman School of Public Health. Charts - Geography of low-income families and children 2003).

4. Greene, Jay, P. (Revised 2002). "High school graduation rates in the United States." Prepared for The Black Alliance for Educational Options. The Manhattan Institute for Policy Research. P. 1-21.

5. School district finances, Proximity, from www.proximityone.com/sdfin.htm

6. State of education. From www.window.state.tx.us/tpr/forces/volume2/focii8.txt

7. Texas demographics, National Center for Children in Poverty, Columbia University Mailman School of Public Health. Charts - Geography of low-income families and children (2003), Income level of families with children in Texas, Percent of children living in low-income families in Texas. 
Notes 